\title{
Robust design of critical factors of multi-stage supply chain operations management
}

\author{
Shahrzad Erfani*, Razieh Keshavarzfard and Sadigh Raissi
}

Department of Industrial Engineering, South Tehran Branch, Islamic Azad University, Tehran, Iran

\begin{tabular}{l}
\hline C H R O N I C L E \\
\hline Article history: \\
Received July 18, 2014 \\
Accepted December 182014 \\
Available online \\
December 182014 \\
\hline Keywords: \\
Supply chain \\
Robust design of parameter \\
Operation management \\
Simulation \\
Optimization \\
\hline
\end{tabular}

\begin{abstract}
A B S T R A C T
Today, supply chains have been widely welcomed by industry researchers and the results of applying it may increase throughput, reduce cost, increase speed to meet customers' needs and create competitive opportunities. This paper identifies a scientific method, which operates efficiently and effectively manages supply chain operations. In this paper, a computer simulation model is analyzed for analyzing the supply chain and the results are examined, accordingly. Using Taguchi design of experiment and running the proposed model under L27 scenarios, a two-objective optimization was performed on the estimated response surfaces, leading to a $60 \%$ increase in productivity and $40 \%$ reduction in waiting time.
\end{abstract}

\section{Introduction}

In the present era of global competition, customer demands on product quality, increase product variety and faster service have increased the pressure on organizations. As a result, organizations cannot afford to do all alone. To achieve a competitive advantage and to gain a larger share of the market, activities such as supply and demand planning, material procurement, production and product planning, inventory control, distribution, delivery which all previously accomplished by the firms now have moved into the supply chain. Key issue in supply chain is correct operation management, which involves identifying the key points of handling and setting them on the appropriate level that promotes the objective indicators. In general, the supply chain is made up of two or more organizations that are legally independent and are related to each other with the flow of material, information and finance. These organizations can be agents of raw materials, components, finished products, or produce services such as distribution, storage, retail and wholesale. Supply chain operations management encompasses the necessary actions can be used to the correct guidance governing processes in the supply chain. This involves identifying the main points of process and set them for the establishment of more favorable conditions. To this purpose, two key questions are raised: what are the key points of the process settings and what is the best value for adjust them? To achieve this important issue, design of parameters and robustness can be used.

* Corresponding author

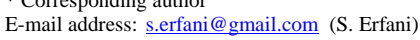

(C) 2015 Growing Science Ltd. All rights reserved. doi: $10.5267 /$ j.uscm.2014.12.005 
Companies require effective management of supply chain processes to increase their competitiveness. One of the important aspects is to determine the best operating conditions for supply chain and it is often difficult because of the complexity of the dynamic interrelationships among members and different parameters of supply chain. In this context, the aim of the present study is to identify critical parameters of supply chain and to determine the optimal level of them using simulation, experimental design and mathematical modeling.

Most studies in the field of supply chain have assumed that supply chain parameters such as production capacity and delivery time are constant and traditional methods of operations research such mathematical programming, stochastic process modeling and simulation have been used to solve supply chain problems. In the present study, in order to avoid obtaining results of applied suggested scenarios in real-world, proposed approach, computer simulations have been used and after testing the validity of the simulation model, new scenarios are arranged using design of experiments of Taguchi. On the simulation results, respond levels are estimated and by applying mathematical optimization techniques, the optimal values of the process parameters have been identified.

This paper is structured as follows:

In the second part, background research is presented. In the third section, the research methodology is presented. The fourth section is devoted to describing the status of Saipa industrial heavy dies manufacturing. In the fifth section, the current state of operations management at the Saipa industrial heavy dies manufacturing is simulated. Test of the validity of the simulation model and simulation results and also modeling and optimization are presented in this section. Finally, conclusions are given in Section sixth.

\section{Literature review}

According to Tsay et al. (1999), supply chain is a series of activities associated with the product and service and also transformation of raw materials to the final product. Chain contains the information required by the production process and encompasses integration of all the above within and outside the company. Cooper et al. (1997) believed that supply chain management was formed of activities and processes inside and outside the organization. Shang et al. (2004) focused on identifying the best operating conditions for the supply chain and used a hybrid approach for integrating simulation, Taguchi method and response level to examine the interaction are among factors to achieve their optimum combinations and to improve the supply chain performance.

Hao and Shen (2008) focused specifically on studying the transportation activities related to the support operation of a manufacturing section using simulation. They showed that applying the JIT (Just-InTime) rules through using Kanban cards in transportation processes, would not only improve the production, but it could also enhance the entire system's efficiency.

Lee and Farahmand (2010) studied an assumed supply chain and investigated the interaction between its inventory control policies and transport strategies and, using simulation tools, offered a decision support system (to support the network management) responsible for the entire supply chain operation. Brito et al. (2010) developed a decision support tool to study strategic issues regarding planning and determining the capacity of supporting and manufacturing equipment for a steel mill using discrete simulation, accidental and multi-criteria decision-making concepts.

Pawlewski and Fertsch (2010) studied the identification and bottlenecks elimination processes using the simulation of a production-logistics system considering all the three strategic, tactical and operational levels. Sharda and Bury (2010) studied the detection and bottlenecks removal issues in the production process of a chemical products factory using computer simulation. 
Nowadays, design and determination of the performance evaluation indices are among the issues considered attractive both in the academic and applied communities as well. What is more important in this connection is the correct and scientific policy making in the operations management to improve the supply chain performance indicators. In the present paper, this has been followed through the parameters robust design and optimization based on the simulation of the supply chain.

\section{Research Methodology}

Since the main objective of this research is to determine a robust operations management parameters, so research is classified in theoretical and descriptive research. Taguchi method is used in a selected supply chain; hence it is also applied research. In this research much of the information is collected based on a sampling of work and interviews with experts and using simulation software package (ED), a three-level supply chain operations management, including raw material supplier, six producers and four costumers is simulated, so while analyzing existing conditions, one can analysis the proposed scenarios before implementation of various aspects. Taguchi method is used to identify the key points of the process and optimal settings and robust design process. In this research, for multi-criteria decision, two response levels have been used then variance and regression analysis method reply to estimate levels of responses. In order to optimize operations management policies, the robust and optimal values for response levels, due to the limitations and using two optimization objective functions using software Lingo are determined.

\section{Case study}

The supply chain of this research is related to press shop of Industrial heavy dies manufacturing. The supply chain of this research is the three-level supply chain, which includes a supplier, a distributer, six manufacturers and four costumers and schematic diagram of that is shown in Fig. 1. The raw material (sheets) is supplied by Saipa Press Company and Saipa logistic company is responsible to distribute sheets and final products throughout the chain. This chain includes six manufacturers where one of them is Industrial Heavy Dies Manufacturing (IHDM) and five producers are contractors for IHDM company. Each of the contractors produces only one type of product and IHDM produces four types of product. Products by contractors and two types of products produced at the IHDM company are sent to Saipa Kashan and the two other types of products produced at the IHDM company are sent to Saipa, Pars khodro and Bonro. According to the experts' view to improve the efficiency of the supply chain, increase productivity and decrease in inventories were considered as the main criteria. Therefore average waiting time of product on the manufacturer's website $\left(\mathrm{Y}_{1}\right)$ and monthly production capacity $\left(\mathrm{Y}_{2}\right)$ were defined as response variables in the system.

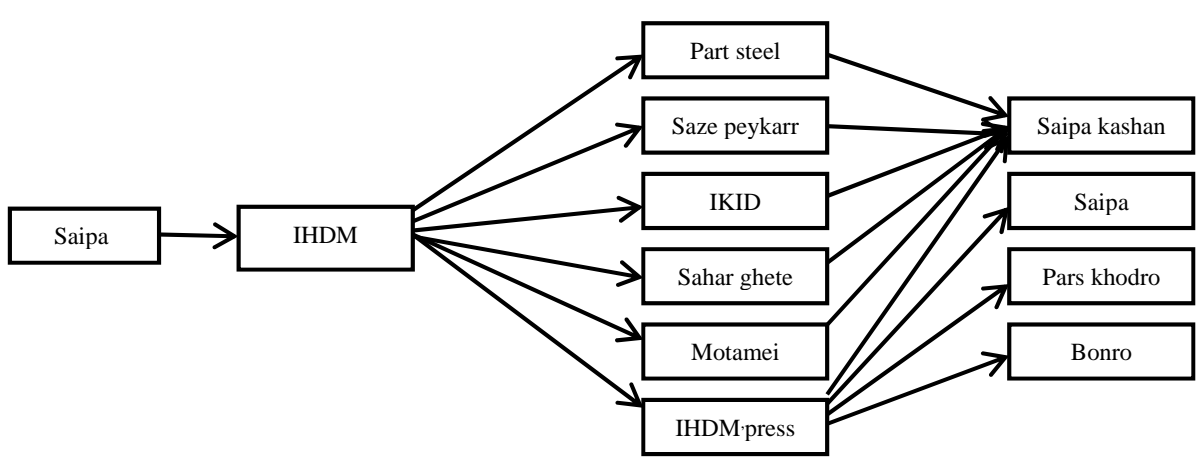

Fig. 1. Supply chain of IHDM 


\section{Design of simulation model}

After analyzing the current supply chain situation, the system layout was designed in the ED simulation software environment (Fig. 2). Among all the demand arrivals and operation times under natural conditions, 150 samples (from each) were collected and underwent the fitness test in the Minitab software environment (with a diagnosis level of 5\%), and the information about random variables were recorded according to the estimated statistical models.

In this model, the raw material (metal sheets) arrival is considered as the identity. To show this arrival (with the model estimated on time lags between demand arrivals), the proposed study has used "Source" atom. After sheets enter the system, they are sent to the manufacturers; the final product is sent to the customers after they are manufactured. Also, to simulate the manufacturing operations, dispatching raw materials to the manufacturers, and sending the final products to the customers (considering the vehicle capacity to reduce logistics costs and make maximum use of resources), "Server" atom has been used and it is shown in the model layout according to the atoms input/output channels adjustments of the material flow.

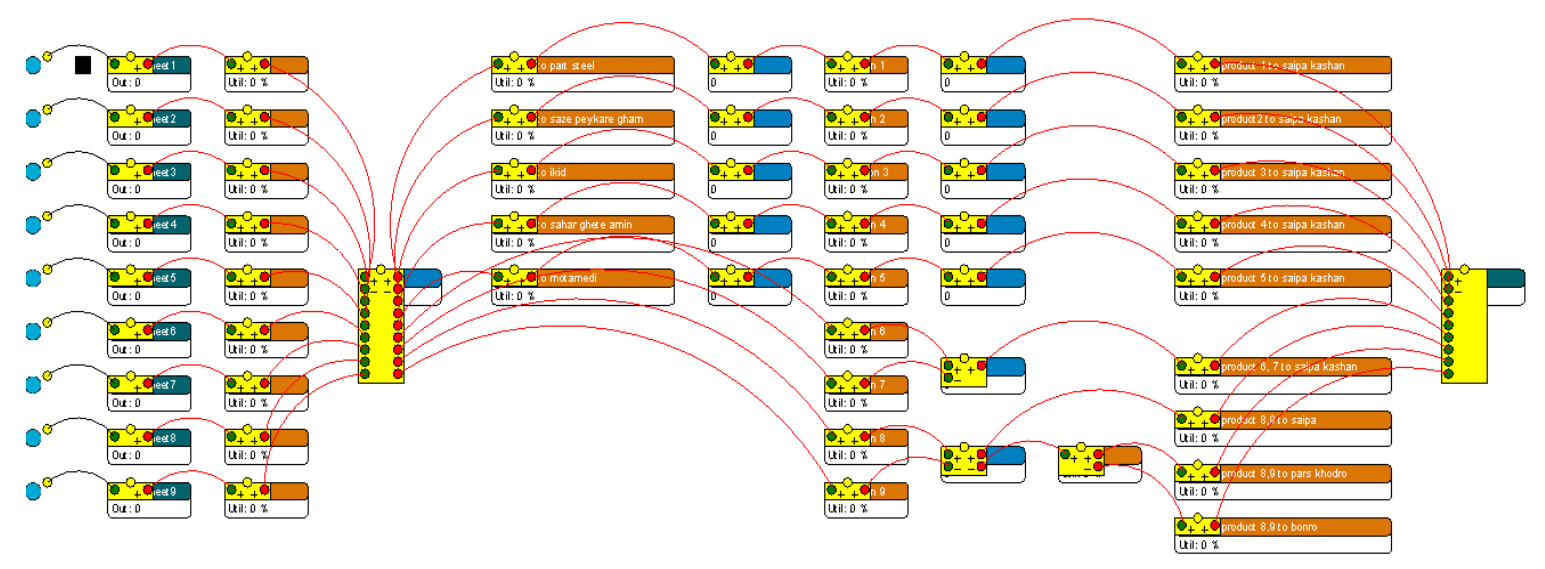

Fig. 2. Saipa IHDM simulation model

To obtain the results, the simulation model was run 15 times for 585 hours, and to remove the bias impact on the results, a period of 15 hours was defined as the system instability. The current situation simulation results have shown that under the current circumstances, the product's average waiting time in the manufacturer's site was 273 seconds, and the monthly production capacity of the supply chain was 7721 products.

As mentioned earlier, this research has been aimed at increasing the monthly production capacity and reducing the product waiting time in the system. In this connection, suggestions, establishing a maintenance system - self-repair, design of repair database, planning for proper use of resources and manpower, were made for the design of experiments based on the changes in the number of operators, repair time in production line, and time lag between failures.

To test the simulation model validation, the study uses Mann-Whitney nonparametric test. In addition the study checks the flow of materials, on the monthly production through comparing the data of 12 months actual production with the results of 15 times simulation runs as regards the difference in the statistical meaningfulness of the mean values with $5 \%$ detection level. Results indicate, statistically, no meaningful difference to validate the model.

It was shown, through examining the possibility of any changes in the current situation and experts' viewpoints, that parameter changes (Table 1) are most possible in product 6 (Side Pride 111) and, 
therefore, test design and optimization were carried out on this production line. Table 1 presents the range of possible changes according to the experts' viewpoints and the proposed plans; these changes are possible and easier both economically and technically.

Table 1

Controllable parameters with their levels

\begin{tabular}{ccccc}
\hline \multirow{2}{*}{ parameter } & description & low & level \\
& mean & up \\
\hline $\mathrm{X}_{1}$ & Average repair time in production line (hour) & 1 & 1.6925 & 2.385 \\
$\mathrm{X}_{2}$ & Mean time between failures on production line (hour) & 3 & 3.5 & 4 \\
$\mathrm{X}_{3}$ & Number of operators in the bottleneck station & 10 & 12 & 14 \\
\hline
\end{tabular}

To design the tests robustly, we have used Taguchi test design method with orthogonal L27 vector for the three variables (in three levels each) (See Table 2). Since there are no explicit mathematical equations for the estimation of the waiting time and the monthly production capacity based on the processing parameters, we have used response level estimations with the help of multivariate regression techniques. Applying this method on Table 2 data set enabled us to estimate the response levels corresponding to Eq. (1) and Eq. (2). The results of ANOVA tests, regression coefficients, and models' residual analyses all show the validity of the estimated regression models when the level of significance is $5 \%$. Therefore, these two objective functions can be optimized to determine the optimal values of the parameters.

Table 2

Supply chain simulation results in 27 designed scenarios

\begin{tabular}{|c|c|c|c|c|c|}
\hline run & $\mathrm{X}_{1}$ & $\mathrm{X}_{2}$ & $\mathrm{X}_{3}$ & $\mathrm{Y}_{1}$ & $\mathrm{Y}_{2}$ \\
\hline 1 & 1 & 3 & 10 & 206.15 & 10216.08 \\
\hline 2 & 1 & 3 & 12 & 191.14 & 10979.17 \\
\hline 3 & 1 & 3 & 14 & 177.47 & 11731.17 \\
\hline 4 & 1 & 3.5 & 10 & 200.23 & 10486.17 \\
\hline 5 & 1 & 3.5 & 12 & 183.49 & 11378.83 \\
\hline 6 & 1 & 3.5 & 14 & 170.10 & 12002.92 \\
\hline 7 & 1 & 4 & 10 & 193.34 & 10853.08 \\
\hline 8 & 1 & 4 & 12 & 179.88 & 11606.92 \\
\hline 9 & 1 & 4 & 14 & 165.9 & 12194.42 \\
\hline 10 & 1.6925 & 3 & 10 & 237.07 & 8877.17 \\
\hline 11 & 1.6925 & 3 & 12 & 22.30 & 9475.83 \\
\hline 12 & 1.6925 & 3 & 14 & 205.85 & 10213.58 \\
\hline 13 & 1.6925 & 3.5 & 10 & 226.93 & 9275.5 \\
\hline 14 & 1.6925 & 3.5 & 12 & 208.95 & 10066.83 \\
\hline 15 & 1.6925 & 3.5 & 14 & 191.27 & 10966.58 \\
\hline 16 & 1.6925 & 4 & 10 & 217.56 & 9689.25 \\
\hline 17 & 1.6925 & 4 & 12 & 200.03 & 10529.17 \\
\hline 18 & 1.6925 & 4 & 14 & 185.68 & 11314.08 \\
\hline 19 & 2.385 & 3 & 10 & 273.02 & 7720.92 \\
\hline 20 & 2.385 & 3 & 12 & 251.15 & 8386.33 \\
\hline 21 & 2.385 & 3 & 14 & 234.31 & 8989.67 \\
\hline 22 & 2.385 & 3.5 & 10 & 256.57 & 8222.83 \\
\hline 23 & 2.385 & 3.5 & 12 & 239.11 & 8805.75 \\
\hline 24 & 2.385 & 3.5 & 14 & 218.36 & 9647.17 \\
\hline 25 & 2.385 & 4 & 10 & 241.95 & 8703.42 \\
\hline 26 & 2.385 & 4 & 12 & 225.35 & 9357 \\
\hline 27 & 2.385 & 4 & 14 & 205.6 & 10233.83 \\
\hline
\end{tabular}

$\mathrm{Y}_{1}=317+38.3 \mathrm{X}_{1}-20.3 \mathrm{X}_{2}-8.28 \mathrm{X}_{3}$ 


$$
\mathrm{Y}_{2}=5489-1715 \mathrm{X}_{1}+877 \mathrm{X}_{2}+368 \mathrm{X}_{3}
$$

The simultaneous optimization of the two linear objective functions was done by Lingo software which resulted in the following optimal values for the process adjustments:

$\mathrm{X}^{*}{ }_{1}=1, \mathrm{X}_{2}^{*}=4, \mathrm{X}_{3}^{*}=14, \mathrm{Y}^{*}{ }_{1}=159.3, \mathrm{Y}^{*}{ }_{2}=12434$.

Results show that the solution consists of 14 operators in the bottleneck station in order to optimize the management of supply chain operations, and maintenance should be performed according to the proposed plan (9). This can cause the average monthly productivity to increase from 7721 to 12,434 and the average waiting time to reduce from 273 to about 160 seconds.

\section{Conclusions}

Since there are complex relationship between policy operations and supply chain performance measures and these relationships are not explicitly known in the supply chain, in this study by using the computer simulation, experimental design of Taguchi, response surfaces methodology and

mathematical optimization in a three-level supply chain, the relationships estimated and strategies for optimizing the operation management were shown. The implementation of this robust parameter design method and optimization of the operations causes a $60 \%$ increase in productivity and $40 \%$ reduction in the waiting time of production in the supply chain.

\section{References}

Brito, T. B., Silva, R. C. D. S., Botter, R. C., Pereira, N. N., \& Medina, A. C. (2010, December). Discrete event simulation combined with multi-criteria decision analysis applied to steel plant logistics system planning. In Proceedings of the Winter Simulation Conference (pp. 2126-2137). Winter Simulation Conference.

Cooper, M. C., Lambert, D. M., \& Pagh, J. D. (1997). Supply chain management: more than a new name for logistics. The International Journal of Logistics Management, 8(1), 1-14

Hao, Q., \& Shen, W. (2008). Implementing a hybrid simulation model for a Kanban-based material handling system. Robotics and Computer-Integrated Manufacturing, 24(5), 635-646.

Lee, E., \& Farahmand, K. (2010, December). Simulation of a base stock inventory management system integrated with transportation strategies of a logistic network. In Simulation Conference (WSC), Proceedings of the 2010 Winter (pp. 1934-1945). IEEE.

Pawlewski, P., \& Fertsch, M. (2010, December). Modeling and simulation method to find and eliminate bottlenecks in production logistics systems. In Simulation Conference (WSC), Proceedings of the 2010 Winter (pp. 1946-1956). IEEE

Shang, J. S., Li, S., \& Tadikamalla*, P. (2004). Operational design of a supply chain system using the Taguchi method, response surface methodology, simulation, and optimization. International Journal of Production Research, 42(18), 3823-3849.

Sharda, B., \& Bury, S. J. (2010, December). Bottleneck analysis of a chemical plant using discrete event simulation. In Proceedings of the Winter Simulation Conference (pp. 1547-1555). Winter Simulation Conference.

Tsay, A. A., Nahmias, S., \& Agrawal, N. (1999). Modeling supply chain contracts: A review. In Quantitative models for supply chain management (pp. 299-336). Springer US. 